\title{
Factor V Leiden mutation in Arabs in Kuwait by real-time PCR: different values for different Arabs
}

\author{
Ali A Dashti, Mehrez M Jadaon and Hend L Lewis \\ Factor V Leiden (FVL) mutation (G1691A) is a risk factor for development of venous thromboembolic disorders. FVL was found \\ mostly in Caucasians (1-15\%) but was almost absent in non-Caucasians. Studies on Arab patients and populations revealed \\ very inconsistent results. This study reports FVL in Arabs living in Kuwait with a focus on the nationality of the Arab subjects \\ studied. Whole-blood samples were collected from 400 healthy Arabs who were 268 Kuwaitis (67\%), 50 Syrians (12.5\%), 34 \\ Jordanians (8.5\%), 8 Palestinians (2\%) and 40 Egyptians (10\%). DNA extraction was carried out for these blood samples and \\ real-time PCR was performed to detect the presence of FVL. Generally, 36 cases $(9 \%$ ) had the mutation ( 33 were heterozygous \\ and 3 were homozygous), with an allelic frequency of 0.049 . The prevalence of FVL differed in different Arabic cases: Kuwaitis \\ $4.5 \%$, Egyptians $15 \%$, Syrians $16 \%$, Jordanians $23.5 \%$ and Palestinians $25 \%$. The allelic frequency was 0.022 in the Kuwaitis \\ and $0.088-0.132$ in non-Kuwaitis. The three homozygous cases were from Syria, Jordan and Egypt. In conclusion, the \\ prevalence of FVL in Arabs living in Kuwait is as high as in Caucasians. There is a difference in prevalence among Arabs \\ themselves, being relatively lower in Kuwaitis than in non-Kuwaitis.
}

Journal of Human Genetics (2010) 55, 232-235; doi:10.1038/jhg.2010.11; published online 12 March 2010

Keywords: Arabs; factor V Leiden mutation; Kuwait; real-time PCR

\section{INTRODUCTION}

In 1994, a point mutation (G1691A) in the gene encoding for the human clotting cofactor V (FV) was discovered and called factor $\mathrm{V}$ Leiden mutation (FVL) after the Dutch city 'Leiden' where it was discovered. ${ }^{1}$ In consequence to this genetic mutation, the translated FV molecule has an 'arginine' amino acid in place of the normal 'glutamine' at the amino-acid residue number 506 of the molecule (Arg506Gln). ${ }^{1,2}$ This apparently simple point mutation was found to lead to a condition called activated protein $\mathrm{C}$ resistance, which causes, in carriers of the mutation, a serious clinical condition known as 'hypercoagulability' or 'thrombophilia', which is very often manifested clinically as venous thromboembolic disorders (VTE). ${ }^{3-6}$ VTE is a significant cause of morbidity and mortality in many countries, including Kuwait, with an annual incidence of 1 out of $1000 .^{3,4,7,8}$ Studies have shown that people with FVL had a higher risk of developing VTE (10-fold and 140-fold increased risk in heterozygous and homozygous carriers, respectively). ${ }^{1,2,5,6,9-12}$

Several studies were conducted worldwide to determine the prevalence and risk of FVL in different countries and ethnic groups. FVL was reported to be highly present in populations of Caucasian origin living in Europe, United States and Australia, with a prevalence of 15-65\% among VTE patients and $1-15 \%$ in the normal populations studied. $1,4,6,7,10-20$ On the other hand, FVL was almost absent in other populations such as Africans, South-East Asians, Chinese, Japanese, American Indians, Greenland Eskimos and Aboriginals of Australia., 77,20-25
In Kuwait, VTE is quite common. Therefore, it may be important to study FVL in Kuwait. Kuwait is an Arabic country containing mostly people of Arabic origin. There were some reports on FVL in Arabs, including one reported by the writers of this article. ${ }^{26-40}$ These reports revealed remarkable variations in the prevalence of FVL in Arabs, being absent in some Arabs (like Saudis and Yemenite), while being present in as high as $27 \%$ of other Arabs (like Lebanese and Palestinians or Israeli Arabs). ${ }^{26-40}$ In our previous study, we found FVL in $15.75 \%$ of Arab patients with VTE and in $2 \%$ of healthy Arab controls, which was lower than the reported figures for Arabs. ${ }^{26}$ However, our previous study was based on conventional PCR and restricted fragment length polymorphism techniques. In this paper, we studied FVL using real-time PCR (RT-PCR), which may be more sensitive than the conventional $\mathrm{PCR} /$ restricted fragment length polymorphism. The numbers obtained here may be compared with other studies on Arabs and may explain why our values in Kuwait differed than the values for Arabs elsewhere.

\section{MATERIALS AND METHODS}

Subjects, blood samples and DNA extraction

A total of 400 healthy Arab volunteers were included in this study, two-third of them were Kuwaitis and the rest were non-Kuwaitis from Syria, Jordan, Palestine and Egypt. There were 200 males and 200 females, with an age range of 17-65 years. These healthy volunteers were students or employees of the Health Sciences Center, Kuwait University, which includes four colleges: 
Medicine, Dentistry, Pharmacy and Allied Health Sciences. None of the volunteers had any family relationships with each other. All volunteers indicated that neither they nor their family members had any history of VTE. One venous blood sample (in an EDTA vacutainer) was obtained from each volunteer using standard phlebotomy. All volunteers signed a consent form indicating their approval of using their blood samples in the project. The study was approved by the ethics committee of the Health Sciences Center, Kuwait University, Kuwait.

Samples were used for DNA extraction either immediately or were kept frozen at $-20{ }^{\circ} \mathrm{C}$ until processed. DNA extraction was performed using a commercial kit (JETQUICK ) for whole blood according to manufacturer's instructions (Genomed, Löhne, Germany). The purity of extracted DNA was analyzed spectrophotometrically at 260 and $280 \AA$. All DNA samples had a 260:280 ratio of 1.6-2.0.

\section{RT-PCR}

Each DNA sample was tested for FVL using RT-PCR. A PCR mixture was prepared for each sample consisting of $5 \mu \mathrm{DNA}$ and $20 \mu \mathrm{l}$ of a mixture of specially designed primers and probes (FACTOR V Q - PCR Alert Kit, Nanogen Advanced Diagnostics SRL, Buttigliera Alta, Italy). Forward and reverse primers were designed by the manufacturer to match an area of the factor $\mathrm{V}$ gene that contains the FVL. Two probes were used: one specific for the wild-type G1691 allele (labeled with FAM fluorophore and blocked by the MGB-NFQ group) and one specific for the mutant A1691 allele (labeled with VIC fluorophore and blocked by the MGB-NFQ group). The mixture was placed in a 96-well PCR plate and the reaction was carried out in an AB 7500 FAST Real-Time PCR System from Advanced Biotechnologies, Foster City, CA, USA. The PCR was run in three steps: first, a pre-read run at $60^{\circ} \mathrm{C}$ for $2 \mathrm{~min}$ (to record the background signal); second, an amplification run starting with one hold at $50{ }^{\circ} \mathrm{C}$ for $2 \mathrm{~min}$ (UNG inactivation) followed by another hold at $95^{\circ} \mathrm{C}$ for $10 \mathrm{~min}$ and concluded with 40 cycles of alternating temperatures: $95^{\circ} \mathrm{C}$ for $15 \mathrm{~s}$ (denaturation) and $60{ }^{\circ} \mathrm{C}$ for $1 \mathrm{~min}$ (annealing and extension); finally, a post-read run at $60^{\circ} \mathrm{C}$ for 2 min (to subtract amplified signals from background signal). Results were analyzed by the RT-PCR machine's software to indicate the presence of one of the following in each DNA sample: wild-type alleles only (normal), mutant alleles only (homozygous FVL) or both alleles (heterozygous FVL).

\section{Statistical analysis}

The percentage of cases with FVL to the total number of cases was calculated. That was done for each nationality, as well as for non-Kuwaitis as a group. Student's $t$-test was performed to compare the percentages (as proportions) of FVL among different nationalities, as well as between Kuwaitis and nonKuwaitis. A $P$-value $<0.05$ was considered as statistical significant. Statistics were performed using EpiCalc 2000 software, version 1.02 (Joe Gilman and Mark Myatt, Brixton books, downloadable free from http://www. brixtonhealth.com/epicalc.html).

In addition, allelic frequencies were calculated for each nationality and for non-Kuwaitis as a group, using the following equation:

Allelic frequency $=($ no. of heterozygous cases $+2 \times$ no. of homozygous cases $) /$ $2 \times$ total no. of cases

\section{RESULTS}

Figure 1 presents a photograph of one of the RT-PCR results. Table 1 summarizes the results of FVL obtained in this study. Among the 400 volunteers included in this study, 36 had FVL (9\%), with an allelic frequency of 0.049 . Positive cases were 12 out of 268 Kuwaitis (4.5\%), 8 out of 50 Syrians (16\%), 8 out of 34 Jordanians (23.5\%), 2 out of 8 Palestinians (25\%) and 6 out of 40 Egyptians (15\%). The prevalence of FVL in non-Kuwaiti Arabs as a group was $18.18 \%$ with an allelic frequency of 0.102 . Table 2 presents the $P$-values of the Student's $t$-test comparing the prevalence of FVL among different nationalities. Although there were no significant differences among non-Kuwaiti Arabs, the prevalence of FVL in Kuwaitis was significantly different from those for each of the non-Kuwaiti groups, as well as the prevalence in non-Kuwaiti Arabs as a whole. Kuwaitis had the lowest prevalence of FVL $(4.5 \%)$, which was significantly less than the prevalence for non-Kuwaitis $(15-25 \%)(P$-value $<0.05)$.

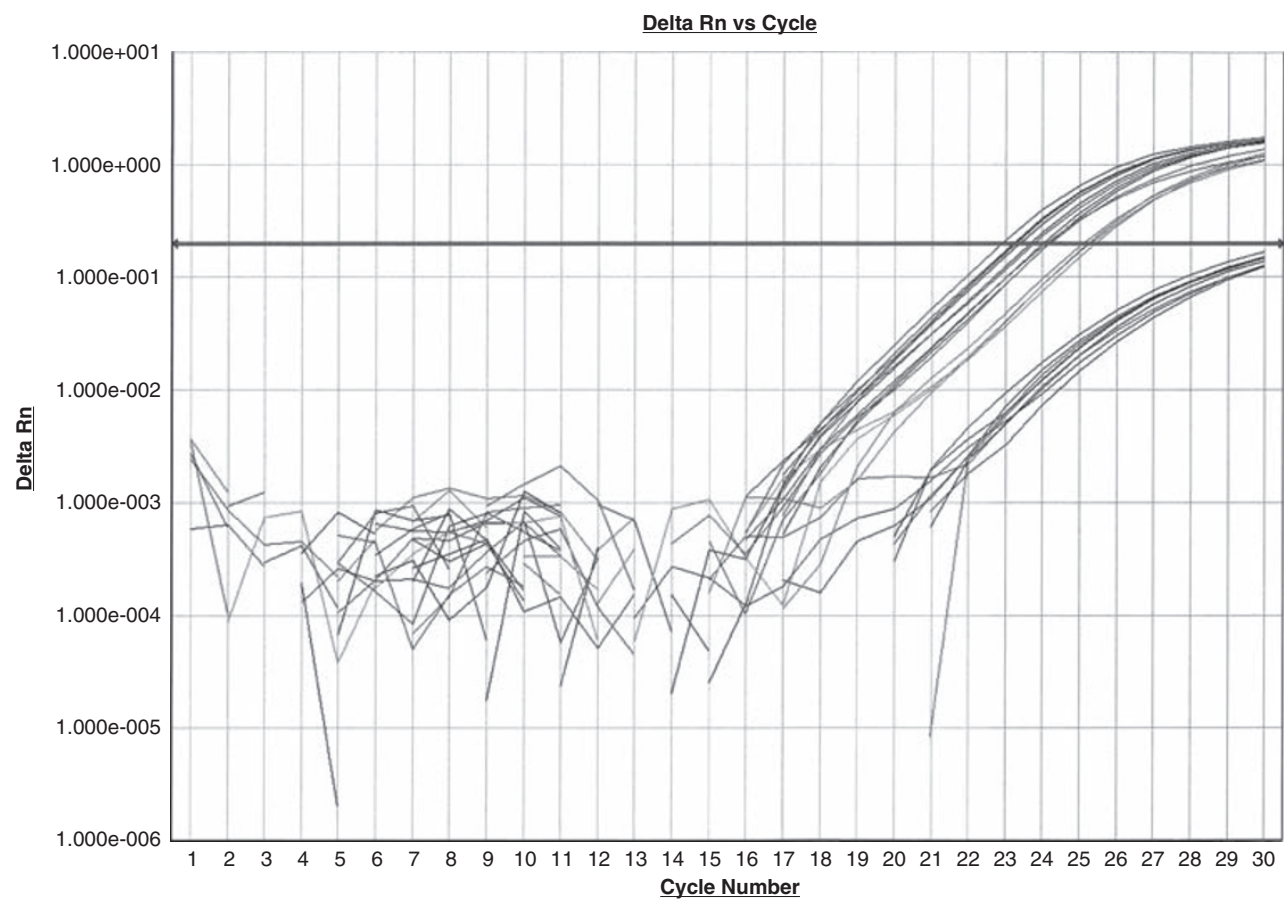

Figure $1 \mathrm{~A}$ graph produced by the RT-PCR machine in one of the experiments. Each line represents one of the samples. When the curve went above the threshold line, it indicated the presence of an allele ( $G$ or $A$ according to the fluorophore detected; refer to the text). Accordingly, cases having only $G$ alleles were normal, whereas those having A alleles were FVL carriers. When both alleles were present in the same case, the case was considered as a heterozygous case. 
Table 1 This table shows the number of subjects included in this study, categorized according to their nationalities. Also, it shows the results for non-Kuwaiti Arabs as a group. The results for FVL in each group are shown, in which the position 1691 of the FV gene had the normal (G) allele on both chromosomes (normal wild-type GG), the mutant FVL (A) allele on both chromosomes (homozygous AA), or one normal (G) allele on one chromosome and one mutant FVL (A) allele on the other chromosome (heterozygous GA). The percentage shown for each result is based on the number of cases of FVL to the total number of cases present for each nationality. Allelic frequencies are also shown in the table.

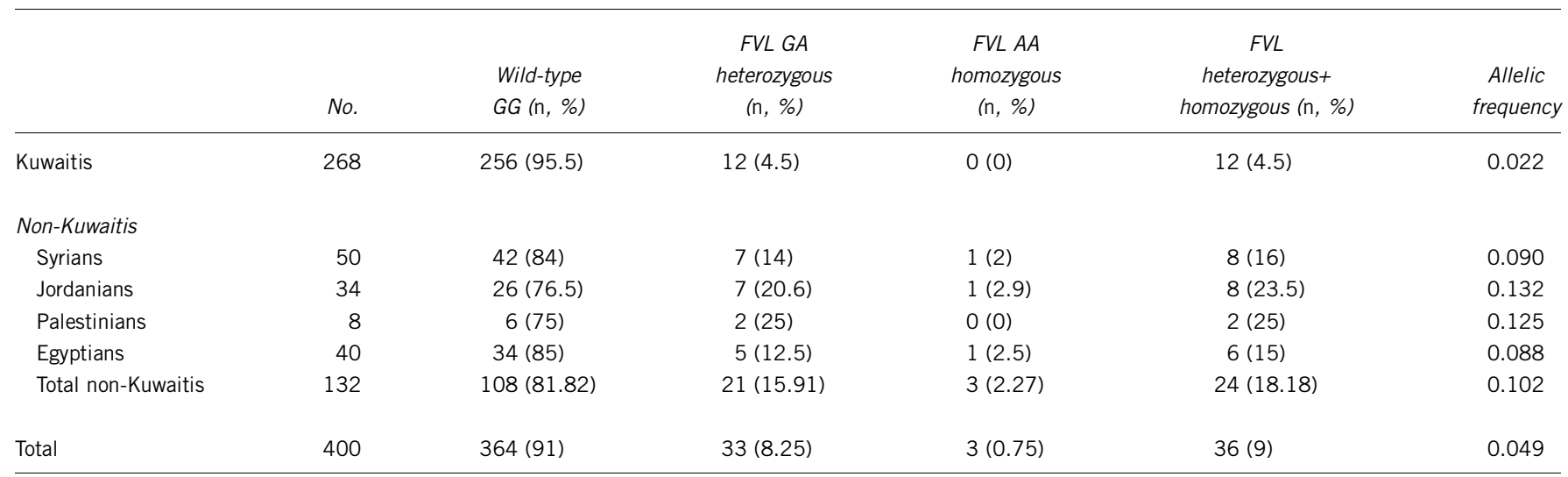

Abbreviation: FVL, factor V Leiden.

Table 2 This table shows the results of Student's $t$-test ( $P$-values) and compares the prevalence of factor $V$ Leiden (FVL) among different nationalities, and between the prevalence of FVL in Kuwaitis and non-Kuwaitis

\begin{tabular}{llccc}
\hline & Kuwaitis & & & \\
Non-Kuwaitis & 0.000 & & & \\
Syrians & 0.003 & Syrians & & \\
Jordanians & 0.00007 & 0.228 & Jordanians & \\
Palestinians & 0.037 & 0.452 & 0.355 & Palestinians \\
Egyptians & 0.000006 & 0.435 & 0.263 & 0.431 \\
\hline
\end{tabular}

Any $P$-value $\leqslant 0.05$ indicates a significant difference.

\section{DISCUSSION}

FVL mutation is an established risk factor for VTE. ${ }^{1-6}$ It is present in a high number of Caucasians, ${ }^{1,4,6,7,10-20}$ but it is very rare in other ethnic groups. ${ }^{7,17,20-25}$ Few studies on Arabs showed that the prevalence of FVL was $0-27 \%$ in different Arabic countries, ${ }^{26-40}$ being as low as zero in countries like Saudi Arabia, ${ }^{7,29,40} \mathrm{Oman}^{34}$ and Yemen, ${ }^{27}$ whereas being relatively very high $(27 \%)$ in Palestinians (Israeli Arabs). ${ }^{27}$ Kuwait is one of the Arabic countries, which is geographically located toward the northeastern part of the Arabic peninsula. In addition to Kuwaitis, many Arabs from different Arabic countries live in Kuwait. In our previous published study, we found FVL in $2 \%$ of the healthy Arabs living in Kuwait. ${ }^{26}$ In this paper, we found FVL in 9\% of healthy Arab volunteers. This difference in numbers between the two studies may be partially explained by the type of laboratory tests we used in the two studies. In the previous study, conventional $\mathrm{PCR} /$ restricted fragment length polymorphism analyses were used, whereas here we used RT-PCR, which may be more sensitive in detecting FVL cases. In addition, it should be mentioned here that in our previous study we did not divide the cases according to their nationalities. When we did so in this study, we got an interesting observation. We found here that there is a significant difference in the prevalence of FVL between Kuwaitis and non-Kuwaitis. The prevalence of FVL in Kuwaitis seems to be much lower than the prevalence in non-Kuwaitis (4.5 vs $15-25 \%$, respectively). The prevalence in Kuwaitis was closer to values reported in Saudi Arabia, Oman, Bahrain and Yemen $(0-3 \%)$, which are geographically present in the Arabic peninsula like Kuwait. ${ }^{7,27,29,34,40}$ The other non-Kuwaiti Arabs included in this study were from Syria, Jordan, Palestine and Egypt, which are geographically present fairly away and toward the northwestern part of the Arabic peninsula (in the eastern part of the Mediterranean Sea). The results for our non-Kuwaiti cases were similar to the values reported by other studies on Arabs from the previously mentioned Eastern Mediterranean Arab countries. ${ }^{27-33,35-40}$ As in our previous study the prevalence of FVL was calculated for Arabs in general (Kuwaitis and non-Kuwaitis together) without accounting for the nationality of cases included, this may explain the lower value of the prevalence of FVL reported by our previous study. Also in that previous study, many Saudi and Yemenite cases were included, which was not the case here. This might have also brought the value down. Therefore, it seems that when studying FVL in Arabs, two major groups should be taken into consideration: one for Arabs living or originating from Arabic countries in the Arabic peninsula (like Kuwait and Saudi Arabia), and one for Arabs living or originating from Arabic countries in the Eastern Mediterranean Sea (including Syria, Lebanon, Palestine, Jordan and Egypt). As a future proposal, it may be of great interest to identify the origin of FVL in Arabs, in particular Arabs in the Mediterranean area, whose ancestors are originally from the Arabian Peninsula and settled in that region much later with the Islamic conquest. It is important to identify a chromosomal locus or polymorphic genetic marker for Arab ancestry to be linked to FVL. This may explain the different values for FVL in these two groups of Arabs.

In conclusion, the prevalence of FVL in Arabs should be studied in accordance with the country of origin. The prevalence is relatively high in Arabs from Syria, Jordan, Palestine and Egypt, and is relatively low in Arabs from Kuwait.

\section{CONFLICT OF INTEREST}

The authors declare no conflict of interest.

\section{ACKNOWLEDGEMENTS}

This work was supported by a grant (project number NM01/06) from the Research Administration of Kuwait University, Kuwait. The authors thank the Research Core Laboratory of the Health Sciences Center, Kuwait University, for performing some of the technical work (project number GM01/01). 
1 Bertina, R. M., Koeleman, B. P. C., Koster, T., Rosendaal, F. R., Dirven, R. J., de Ronde, H. D. et al. Mutation in blood coagulation factor $\mathrm{V}$ associated with resistance to activated protein C. Nature 369, 64-67 (1994).

2 Dahlbäck, B., Carlsson, M. \& Svensson, P. J. Familial thrombophilia due to a previously unrecognized mechanism characterized by poor anticoagulant response to activated protein C: prediction of a cofactor to activated protein C. Proc. Natl Acad. Sci. USA 90 1004-1008 (1993).

3 Dahlbäck, B. Resistance to activated protein C, the Arg506 to GIn mutation in the factor $\mathrm{V}$ gene, and venous thrombosis. Functional tests and DNA-based assays. Pros and Cons. Thromb. Haemost. 73, 739-742 (1995).

4 Ridker, P. M., Miletich, J. P., Hennekens, C. H. \& Buring, J. E. Ethnic distribution of factor $\mathrm{V}$ Leiden in 4047 men and women. Implications for venous thrmoboembolism screening. JAMA 277, 1305-1307 (1997).

5 Dahlbäck, B. Resistance to activated protein C caused by the factor V R506Q mutation is a common risk factor for venous thrombosis. Thromb. Haemost. 78, $483-488$ (1997).

6 Faioni, E. M., Razzari, C., Martinelli, I., Panzeri, D., Franchi, F. \& Mannucci, P. M. Resistance to activated protein $\mathrm{C}$ in unselected patients with arterial and venous thrombosis. Am. J. Hematol. 55, 59-64 (1997).

7 Rees, D. C., Cox, M. \& Clegg, J. B. World distribution of factor V Leiden. Lancet 346, 1133-1134 (1995).

8 Zivelin, A., Griffin, J. H., Xu, X., Samama, M., Conard, J., Brenner, B. et al. A single genetic origin for a common Caucasian risk factor for venous thrombosis. Blood $\mathbf{8 9}$, 397-402 (1997).

9 Hoagland, L. E., Triplett, D. A., Peng, F. \& Barna, L. APC-resistnace as measured by a Textarin time assay: comparison to the APTT-based method. Thromb. Res. 83, 363-373 (1996).

10 Zöller, B., Svensson, P. J., He, X. \& Dahlbäck, B. Identification of the same factor V gene mutation in 47 out of 50 thrombosis-prone families with inherited resistance to activated protein C. J. Clin. Invest. 94, 2521-2524 (1994).

11 Alderborn, A., Siegbahn, A. \& Wadelius, C. Venous thrombosis: factor V G1691A genetypeing related to APC resistance measured by 2 methods. Eur. J. Haematol. 58, 229-232 (1997).

12 Bontempo, F. A., Hassett, A. C., Faruki, H., Steed, D. L., Webster, M. W. \& Makaroun, M. S. The factor $V$ Leiden mutation: spectrum of thrombotic events and laboratory evaluation. J. Vasc. Surg. 25, 271-275 (1997).

13 Florell, S. R. \& Rodgers, G. M. Inherited thrombotic disorders: an update. Am. J. Hematol. 54, 53-60 (1997).

14 Samama, M. M., Simon, D., Horellou, M. H., Trossaërt, M., Elalamy, I. \& Conard, J. Diagnosis and clinical characteristics of inherited activated protein $\mathrm{C}$ resistance. Haemostasis 26, 315-330 (1996).

15 Dahlbäck, B., Hillarp, A., Rosen, S. \& Zöller, B. Resistance to activated protein C, the FV:Q506 allele, and the venous thrombosis. Ann. Hematol. 72, 166-176 (1996).

16 Koeleman, B. P. C., Reitsma, P. H. \& Bertina, R. M. Familial thrombophilia: a complex genetic disorder. Semin. Hematol. 34, 256-264 (1997).

17 Cox, M. J., Rees, D. C., Martinson, J. J. \& Clegg, J. B. Evidence of a single origin of factor V Leiden. Br. J. Haematol. 92, 1022-1025 (1996).

18 Simioni, P., Prandoni, P., Lensing, A. W., Scudeller, A., Sardella, C., Prims, M. H. et al. The risk of recurrent venous thromboembolism in patients with an Arg506 $\rightarrow$ G mutation in the gene for factor V (factor V Leiden). N. Engl. J. Med. 336, 399-403 (1997).

19 Leroyer, C., Mercier, B., Escoffre, M., Férec, C. \& Mottier, D. Factor V Leiden prevalence in venous thromboembolism patients. Chest. 111, 1603-1606 (1997).

20 Bennett, J. A., Palmer, L. J., Musk, A. W. \& Erber, W. N. Prevalence of factor V Leiden and prothrombin 20210A mutations in indigenous Australians. Thromb. Haemost. 86, 1592-1593 (2001).

21 Arruda, V. R., Annichino-Bizzacchi, J. M., Costa, F. F. \& Reitsma, P. H. Factor V Leiden (FVQ 506) is common in a Brazilian population. Am. J. Hematol. 49, 242-243 (1995).
22 Zama, T., Murata, M., Ono, F., Watanabe, K., Watanabe, R., Moriki, T. et al. Low prevalence of activated protein $C$ resistance and coagulation factor $V$ Arg506 to GIn mutation among Japanese patients with various forms of thrombosis, and normal individuals. Int. J. Hematol. 65, 71-78 (1996).

23 Pepe, G., Rickards, O., Vanegas, O. C., Brunelli, T., Gori, A. M., Giusti, B. et al. Prevalence of factor $V$ Leiden mutation in non-European populations. Thromb. Haemost. 77, 329-331 (1997).

24 Ho, C. H., Chau, W. K., Hsu, H. C., Gau, J. P. \& Chih, C. M. Prevalence of factor V Leiden in the Chinese population. Zhonghua. Yi. Xue. Za. Zhi. 62, 875-878 (1999).

25 De Maat, M. P. M., Kluft, C., Jespersen, J. \& Gram, J. World distribution of factor V Leiden mutation. Lancet. 347, 58 (1996).

26 Jadaon, M. M., Dashti, A. A. \& Lewis, H. L. High prevalence of activated protein C resistance and factor $\mathrm{V}$ Leiden mutation in Arab population and patients with venous thrombosis in Kuwait. Diag. Mol. Pathol. (in press) (2010).

27 Rosen, E., Renbaum, P., Heyd, J. \& Levy-Lahad, E. High frequency of factor V Leiden in a population of Israeli Arabs. Thromb. Haemost. 82, 1768 (1999).

28 Almawi, W. Y., Tamim, H., Kreidy, R., Timson, G., Rahal, E., Nabulsi, M. et al. A case control study on the contribution of factor V-Leiden, prothrombin G20210A, and MTHFR C677T mutations to the genetic susceptibility of deep venous thrombosis. J. Thromb. Thrombolysis. 19, 189-196 (2005).

29 Dzimiri, N. \& Meyer, B. World distribution of factor V Leiden. Lancet. 347, 481-482 (1996).

30 Irani-Hakime, N., Tamim, H., Elias, G., Finan, R. R., Daccache, J. L. \& Almawi, W. Y. High prevalence of factor $\mathrm{V}$ mutation (Leiden) in the Eastern Mediterranean. Clin. Chem. 46, 134-136 (2000).

31 Taher, A., Khalil, I., Shamseddine, A., El-Ahdab, F. \& Bazarbachi, A. High prevalence of factor $V$ Leiden mutation among healthy individuals and patients with deep venous thrombosis in Lebanon: is the eastern Mediterranean region the area of origin of this mutation? Thromb. Haemost. 86, 723-724 (2001).

32 Eid, S. S. \& Shubeilat, T. Prevalence of factor V Leiden, prothrombin G20210A, and MTHFR G677A among 594 thrombotic Jordanian patients. Blood Coagul. Fibrinolysis. 16, 417-421 (2005).

33 El-Karaksy, H., El-Koofy, N., El-Hawary, M., Mostafa, A., Aziz, M., El-Shabrawi, M. et al. Prevalence of factor $\mathrm{V}$ Leiden mutation and other hereditary thrombophilic factors in Egyptian children with portal vein thrombosis: results of a single-center case-control study. Ann. Hematol. 83, 712-715 (2004).

34 Pathare, A., Al Kindi, S., Al Haddabi, H., Dennison, D., Bayoumi, R. \& Muralitharan, S. Hereditary thrombophilia in ethnic Omani patients. Am. J. Hematol. 81, 101-106 (2006).

35 Settin, A., Dowaidar, M., El-Baz, R., Abd-Al-Samad, A., El-Sayed, I. \& Nasr, M. Frequency of factor $V$ Leiden mutation in Egyptian cases with myocardial infarction. Hematology 13, 170-174 (2008).

36 Tamim, H., Finan, R. R. \& Almawi, W. Y. Prevalence of two thrombophilia predisposing mutations: factor V G1691A (R506Q; Leiden) and prothrombin G20210A, among healthy Lebanese. Thromb. Haemost. 88, 691-692 (2002).

37 Finan, R. R., Tamim, H., Ameen, G., Sharida, H. E., Rashid, M. \& Almawi, W Y Prevalence of factor V G1691A (factor V-Leiden) and prothrombin G20210A gene mutations in a recurrent miscarriage population. Am. J. Hematol. 71, 300-305 (2002).

38 Eid, S. S. \& Rihani, G. Prevalence of factor V Leiden, prothrombin G20210A, and MTHFR C677T mutations in 200 healthy Jordanians. Clin. Lab. Sci. 17, 200-202 (2004).

39 Awidi, A., Shannak, M., Bseiso, A., Kailani, M. A. M., Kailani, M. A., Omar, N. et al. High prevalence of factor V Leiden in healthy Jordanian Arabs. Thromb. Haemost. 41, 582-584 (1999).

40 Almawi, W. Y., Keleshian, S. H., Borgi, L., Fawaz, N. A., Abboud, N., Mtiraoui, N. et al. Varied prevalence of factor V G1691A (Leiden) and prothrombin G20210A single nucleotide polymorphisms among Arabs. J. Thromb. Thrombolysis 20, 163-168 (2005). 